\title{
Point of View Discovery
}

\section{Parakrama Chandrasoma}

Los Angeles County - University of Southern California Medical Center and Keck School of Medicine, University of Southern California, Los Angeles, California, USA

DOI: http://doi.org/10.4038/jdp.v11i1.7692

Submitted on 28.02.2016 Accepted for publication on 01.05.2016

Discovering something that impacts patient care in a positive manner is the most wondrous thing a physician can achieve. Discovery is not limited to well funded researchers working with sophisticated technology. It is available to everybody in the practice of medicine.

The most powerful discoveries in history have been made by physicians who were not looking for discovery. Edward Jenner, a country physician in England, noticing that milkmaids were immune to small pox led to the development of vaccination. Ignacio Semmelweiss, a medical student, noticing that midwives in a poor delivery center in Vienna had a much lower rate of puerperal sepsis than in the University obstetrics department figured out that it was simply because they washed their hands between deliveries.

Such discoveries are available to all physicians wherever they practice. It requires a strong primary medical education that instills a healthy curiosity, an open mind, and the courage to follow an observation that has a different meaning than what everyone else in the world believes. With these characteristics, one must be ready to

Author for correspondence:

Parakrama Chandrasoma, MD (Sri Lanka), MRCP (UK), FACP (USA). Los Angeles County - University of Southern California Medical Center and Professor Emeritus of Pathology, Keck School of Medicine, University of Southern California, Los Angeles, California, USA. E mail: ptchandr@usc.edu recognize the opportunity for discovery that presents itself and then pounce on it with vigour. I am certain that many physicians frequently see things that can lead to discovery if their minds are prepared.

\section{Dr DeMeester comes to the University of Southern California}

In 1990, I was a surgical pathologist in a busy public hospital in Los Angeles. I had no thought of discovery. I did no research. I had never applied for grant funding. My interests were patient care and teaching.

A new University Hospital had been built at the University of Southern California and $\mathrm{Dr}$ Tom DeMeester, a world-renowned esophageal surgeon was recruited as Chairman of Surgery. I was assigned to do his pathology. Dr DeMeester's main interest was gastro-oesophageal reflux disease (GORD). He had pioneered the use of manometry and 24hour $\mathrm{pH}$ testing and had perfected the antireflux procedure developed by Nissen $(1,2)$. He was also a compulsively thorough investigator. Unlike anyone else in the world, he followed his own biopsy protocol in every patient that he endoscoped. He took biopsies from everyone. In endoscopically normal patients, he biopsied the squamocolumnar junction (SCJ), the distal stomach, and took a retroflex biopsy from within $1 \mathrm{~cm}$ distal to the $\mathrm{SCJ}$ in what everyone, including myself, believed was the proximal stomach. He had done these biopsies for 20 years. Though these had not provided any useful 
information, he persisted in doing them. It was as if some inner voice told him that it made no sense that there was no pathology in a disease caused by oesophageal epithelium being repeatedly exposed to strongly acidic gastric juice.

Knowing I would be reading his biopsies, I reviewed the entire literature on GORD. At the time, it was believed without doubt that the distal $2 \mathrm{~cm}$ of the oesophagus and proximal $3 \mathrm{~cm}$ of the stomach were normally lined by cardiac epithelium. I had no reason to think this was not true.

An observation from the biopsies: cardiac epithelium is not present to the extent implicitly believed by the world

Over the next years, I received biopsies from 4-8 patients per day from $\mathrm{Dr}$. DeMeester's unit. Initially, these seemed to confirm what the literature stated. People who were endoscopically normal had the oesophageal squamous epithelium transition into cardiac epithelium at the gastrooesophageal junction (GOJ) and the retrograde biopsy taken within $1 \mathrm{~cm}$ distal to the SCJ showed cardiac epithelium. There was no pathology except that cardiac epithelium always showed chronic inflammation and frequently showed reactive changes. This did not raise any questions in my mind; the mucosa of the gastrointestinal tract is notoriously variable in the number of inflammatory cells. It should have because when gastric oxyntic epithelium was present in these biopsies, there was no inflammation at all except in patients who had Helicobacter pylori gastritis.

Within a few months, however, the negative started becoming apparent. Patients whose biopsies showed very little cardiac epithelium were not uncommon and more rarely, there were patients who had no cardiac epithelium at all. How was this possible when the normal extent of cardiac epithelium was $5 \mathrm{~cm}$ ? My first reaction was that the biopsies were being done incorrectly.
This was quickly proven wrong by a single visit to the endoscopy suite. The two biopsies at the $\mathrm{SCJ}$ and $1 \mathrm{~cm}$ distal were separated by a maximum of $1 \mathrm{~cm}$.

The discovery: cardiac epithelium is an abnormal GORD-induced epithelium in the esophagus; it is never normal and never gastric

The observation had suddenly become a discovery: cardiac epithelium was not normally present over $5 \mathrm{~cm}$ between squamous epithelium and gastric oxyntic epithelium. There was an obvious problem with present understanding. A review of the literature showed that the dogma that $5 \mathrm{~cm}$ of cardiac epithelium was normally present had no basis in evidence whatsoever (3). It was just something everyone simply believed without question.

We immediately undertook an autopsy study of the GOJ in patients without clinical evidence of GORD during life (4). This showed that cardiac epithelium was absent distal to the SCJ in $56 \%$ of people and when present, was less than $0.9 \mathrm{~cm}$. A study from Cleveland Clinic confirmed that the length of cardiac epithelium in children was $<0.4 \mathrm{~cm}$ (5). A study of asymptomatic volunteers from Glasgow showed that the length of cardiac epithelium was a mean of $0.175 \mathrm{~cm}$ in nonobese patients and $0.25 \mathrm{~cm}$ in obese patients (6). The dogma that cardiac epithelium was present in an extent $5 \mathrm{~cm}$ was debunked; its extent in normals was $<1 \mathrm{~cm}$ and sometimes zero.

A second study showed that endoscopically normal patients who did not have cardiac epithelium in their biopsies were physiologically more likely to be normal than those who did. Patients with cardiac epithelium of any extent had higher 24-hour $\mathrm{pH}$ scores and lower esophageal sphincter abnormalities. This showed that any cardiac epithelium distal to the SCJ is abnormal and was a metaplastic epithelium resulting from exposure of esophageal squamous epithelium 
to gastric juice. The inflammation in cardiac epithelium was GORD-induced damage. We termed this reflux carditis (7).

\section{The length of cardiac epithelium distal to the $\mathrm{SCJ}$ is directly related to the severity of GERD}

While the normal person had very little cardiac epithelium, it was clear that many people has greater than the normal extent of cardiac epithelium. Jain et al showed that cardiac epithelium was present in biopsies at the endoscopic GOJ, $1 \mathrm{~cm}$ distal and $2 \mathrm{~cm}$ distal to the GOJ in $35 \%, 14 \%$ and $3 \%$ of patients (8). Data quickly accumulated that the length of cardiac epithelium distal to the SCJ increased with increasing severity of GORD. Glickman et al showed that children with $>0.1 \mathrm{~cm}$ of cardiac epithelium had significantly more active esophagitis than those with $<0.1 \mathrm{~cm}$ (9). We showed that patients with $>2 \mathrm{~cm}$ of cardiac epithelium had a much higher esophageal acid exposure in a 24-hour $\mathrm{pH}$ test than those with $<2 \mathrm{~cm}$ $(10,11)$.

\section{The present definition of the GOJ must be wrong}

The finding that an increase in the length of cardiac epithelium distal to the endoscopic GOJ correlated with increasing severity of GORD made no sense. Reflux of gastric juice into the esophagus cannot produce pathology in the proximal stomach.

The obvious answer to this conundrum was that the presently used definition of the GOJ must be wrong. Careful review of the literature traced the sources of the two commonly used definitions of the GOJ at endoscopy. The first definition, the end of the tube where it flares into the saccular stomach, was stated by Hayward in 1961 (3). He produced no data whatsoever to prove that the end of the tube was the oesophagus. The second definition, the proximal limit of rugal folds, was attributed to a paper by McClave et al in 1987 (12). Again, this had no evidence base in support. All authorities agree that there is no evidence base for the present endoscopic definitions of the GOJ, but recommend their use. The proximal limit of rugal folds is universally used by endoscopists to define the GOJ.

We studied 10 selected oesophagectomy specimens where there was a clear point of flaring of the tubal esophagus that was concordant with the proximal limit of rugal folds. Histologic study showed that cardiac epithelium extended distal to the end of the tube for 0.36 to $2.05 \mathrm{~cm}$. Two patients with squamous carcinoma (not GORD-associated) had lengths of 0.36 to $0.43 \mathrm{~cm}$, similar to autopsy and asymptomatic volunteers. 8 patients with adenocarcinoma secondary to Barrett oesophagus had lengths of 1.03 to $2.05 \mathrm{~cm}$. The area distal to the end of the tube that was lined by cardiac epithelium contained oesophageal submucosal glands whose extent was concordant with the length of cardiac epithelium distal to the end of the tube (13).

The dilated distal oesophagus: a new clinical entity is born

The pathology of GORD is completely misunderstood. By believing in two false dogmas, the early pathologic changes of GORD are misinterpreted as normal proximal stomach. The discovery has provided powerful evidence that has eradicated these two dogmas. Cardiac epithelium is never a normal proximal gastric epithelium; it is a metaplastic GORD induced oesophageal epithelium. The $\mathrm{GOJ}$ is not the proximal limit of rugal folds; it is histologically defined as the proximal limit of gastric oxyntic epithelium (14).

Eradication of these dogmas results in the recognition that the variable area between the endoscopic GOJ and the true GOJ that is lined by cardiac epithelium is the GORDdamaged dilated distal oesophagus. This is a new clinico-pathologic entity $(15,16)$. The dilated distal oesophagus is caused by the loss of sphincter tone in the distal oesophagus. Loss of sphincter tone is related to columnar metaplasia because the length of cardiac 
epithelium is concordant with the length of the dilated distal oesophagus. When the dilated distal oesophagus is short, the patient is asymptomatic and has no reflux into the esophageal body, i.e. the $\mathrm{pH}$ test is normal (this is subclinical GORD). When it elongates, the likelihood of symptoms of GORD and reflux into the oesophagus increases.

\section{Pathologic assessment of lower oesophageal sphincter damage}

Lower oesophageal sphincter damage is well recognized as the cause of GORD. There is, however, no test at the present time that provides a measure of sphincter damage. Manometry measures the length of the functioning residual sphincter; the damaged sphincter that has lost pressure is equivalent to the stomach at manometry. As a result, manometry presently has little or no use as a diagnostic test for GORD.

The length of the dilated distal oesophagus can be measured by appropriate multi-level biopsies taken distal to the SCJ in endoscopically normal people. This would represent a pathologic measure of damage to the lower oesophageal sphincter.

Having a new pathologic assessment of lower oesophageal sphincter damage can transform the management of GORD. By its ability to accurately assess severity of the cause of GORD before symptoms develop, it can diagnose GORD earlier. Early diagnosis can lead to identification of criteria that can predict which patients are most likely to progress to severe GORD with failure of medical therapy, Barrett esophagus and adenocarcinoma in the future. Theoretically, this permits the development of measures that can stop progression of sphincter damage and prevent the development of severe GORD, including adenocarcinoma in selected high-risk patients.

\section{The future}

New ideas and concepts take a long time before they are accepted. The application of this discovery and its ramifications in terms of evaluating and managing GORD in a manner that is different than at present are likely to take many years.

Procrastination by some means opportunity for others. This discovery did not need anyone in the USA. A Dr. DeMeester equivalent in Sri Lanka to do the biopsies and any curious pathologist reading the biopsies could have developed these ideas. All that is needed is a patient, an endoscope, curiosity to take the biopsies that no one else takes, an open mind when reading the biopsies, and the courage to follow through. The road may be hard, but it is available to everyone anywhere in the world.

Discovery is marvelous. Go for it!

\section{References}

1. Jamieson JR, Stein HJ, DeMeester TR et al. Ambulatory 24-hour esophageal $\mathrm{pH}$ monitoring: normal values, optimal thresholds, specificity, sensitivity, and reproducibility. Am J Gastroenterol 1992;87:1102-1111.

2. Zaninotto G, DeMeester TR, Schwizer W. et al. The lower esophageal sphincter in health and disease. Am J Surg 1988;155:104-111.

3. Hayward J. The lower end of the oesophagus. Thorax 1961;16:36-41.

4. Chandrasoma PT, Der R, Ma Y, et al. Histology of the gastroesophageal junction: an autopsy study. Am J SurgPathol 2000;24:402-409.

5. Kilgore SP, Ormsby AH, Gramlich TL, et al. The gastric cardia: fact or fiction? Am J. Gastroenterol 2000;95:921-924.

6. Robertson EV, Derakhshan $\mathrm{MH}$, Wirz AA, et al. Central obesity in asymptomatic volunteers is associated with increased intrasphincteric acid reflux and lengthening of cardiac mucosa. Gastroenterology 2013;145:730-739.

7. Oberg S, Peters JH, DeMeester TR, et al. Inflammation and specialized intestinal metaplasia of cardiac mucosa is a manifestation of gastroesophageal reflux disease. Ann Surg 1997;226:522-532. 
8. Jain R. Aquino D, Harford WV, Lee E, Spechler SJ. Cardiac epithelium is found infrequently in the gastric cardia. Gastroenterology 1998;114:A160 (Abstract).

9. Glickman JN, Fox V, Antonioli DA, Wang $\mathrm{HH}$, Odze RD. Morphology of the cardia and significance of carditis in pediatric patients. Am J SurgPathol 2002;26:1032-1039.

10. Chandrasoma PT, Lokuhetty DM, DeMeester, TR, et al. Definition of histopathologic changes in gastroesophageal reflux disease. Am J. SurgPathol 2000;24:344-351.

11. Der R, Tsao-Wei DD, DeMeester $T$, et al. Carditis: a manifestation of gastroesophageal reflux disease. Am J SurgPathol 2001;25:245252.

12. McClave SA, Boyce HW Jr, Gottfried MR. Early diagnosis of columnar lined esophagus: A new endoscopic diagnostic criterion. GastrointestEndosc 1987;33:413-416.

13. Chandrasoma $P, \quad$ Makarewicz K, Wickramasinghe K. Ma YL, DeMeester TR. A proposal for a new validated histologic definition of the gastroesophageal junction. Human Pathol 2006;37:40-47.

14. Chandrasoma P. Controversies of the cardiac mucosa and Barrett's esophagus. Histopathol 2005;46:361-373.

15. Chandrasoma PT. Histologic definition of gastroesophageal reflux disease. CurrOpinGastroenterol 2013;29:460-467.

16. Chandrasoma $P$, Wijetunge $S, M a Y$, et al. The dilated distal esophagus: a new entity that is the pathologic basis of early gastroesophageal reflux disease. Am J SurgPathol 2011;35:18731881.

\# 